\title{
The macular threshold protocol of the Humphrey visual field analyzer: a superior functional outcome of intravitreal bevacizumab for the treatment of neovascular age-related macular degeneration
}

\author{
Desfecho funcional superior da eficácia do tratamento com bevacizumab \\ intravítreo em degeneração macular relacionada à idade, por meio \\ do protocolo de limiar macular do campímetro de Humphrey
}

\author{
Fabio Lavinsky ${ }^{1}$ \\ Micheal John Tolentino ${ }^{2}$ \\ Jaco Lavinsky ${ }^{3}$
}

\begin{tabular}{l} 
ABSTRACT \\
\hline Purpose: To evaluate the decibel loss on the Macular threshold protocol \\
of the Humphrey visual field as a reliable functional outcome of the \\
intravitreal bevacizumab treatment. Methods: Thirteen patients were \\
evaluated at baseline and on the week 6 for best corrected visual acuity, \\
optical coherence tomography central macular thickness and decibel \\
loss on Macular threshold protocol of the Humphrey visual field after \\
1.25 mg intravitreal injection of bevacizumab. The outcomes were \\
analyzed separately and in correlation using the Wilcoxon signed ranks \\
test. Results: The improvement of the optical coherence tomography \\
and the Macular threshold protocol of the Humphrey visual field from \\
baseline to week 6 were significant with $p=0.032$ and $p=0.003$, res- \\
pectively. The visual acuity did not show a significant improvement. \\
The correlation of the visual acuity and Macular threshold protocol of \\
the Humphrey visual field was significant at baseline ( $p=0.041)$ and on \\
week 6 ( $p=0.019$ ). Conclusion: The Macular threshold protocol of the \\
Humphrey visual field significantly improved despite the fact that the \\
best corrected visual acuity did not. The Macular threshold protocol of \\
the Humphrey visual field correlated with the visual acuities signi- \\
ficantly. The optical coherence tomography was significant to demons- \\
trate improvement but did not correlate with best corrected visual acuity \\
and Macular threshold protocol of the Humphrey visual field. These \\
findings suggest that the Macular threshold protocol of the visual field \\
may be a more reliable tool for evaluation of global macular function \\
after intravitreal bevacizumab treatment.
\end{tabular}

Keywords: Macular degeneration; Tomography, optical; Vitreous body; Visual acuity; Perime-

try; Injections; Choroidal neovascularisation; Antibodies, monoclonal
Institution: Ophthalmology Department. Hospital de Clínicas de Porto Alegre - Porto Alegre (RS) - Brazil.

The Goldschleger Eye Institute, Sheba Medical Center, Tel Aviv University - Tel Hashomer - Israel.

Center of Retina and Macular Disease, Winter Haven, Florida - United States of America.

Ophthalmology Department. Hospital de Clínicas de Porto Alegre - Porto Alegre (RS) - Brazil.

Correspondence address: Fabio Lavinsky. Hacarmel Street, 8 - Apt 22 - Ganei Tikva - Israel

E-mail: ylavinsky@hotmail.com

Financial support: none

\footnotetext{
Age-related macular degeneration (AMD) is a complex multistage disease ranging from early subclinical alterations at the choroidea-retinal pigment epithelium (RPE) interface to advanced atrophic or fibrovascular changes associated with a degenerated and functionally inactive central retina $^{(1)}$. Choroidal neovascularization is the hallmark of exudative AMD and indicates the growth of new blood vessels from the choroid. The newly
} 
formed neovascular complex may extend into the pigment epithelial and subretinal spaces ${ }^{(2)}$. The new vessels usually leak serous fluid, bleed and evolve into fibrovascular tissue. The choroidal neovascularization (CNV) finally involutes into a dense submacular disciform scar that usually represents the end stage of the disease ${ }^{(3)}$. Several factors such as ischemia, inflammation and local synthesis and secretion of angiogenic factors are supposed to be important in the pathogenesis of CNV. One of the most prominent stimulators of angiogenesis is the vascular endothelial growth factor (VEGF). Vascular endothelial growth factor $\mathrm{A}$ is believed to contribute to the development and/or progression of the choroidal neovascularization associated with neovascular (wet or exudative) $\mathrm{AMD}^{(4-8)}$.

The successful introduction of anti-VEGF therapy for exudative AMD led to a conceptual revolution of how to approach this and other neovascular ocular diseases. The blockade of free VEGF with an aptamer (pegaptanib), antibody (bevacizumab) or antibody fragment (ranibizumab) are mainstream treatment modalities for wet $\mathrm{AMD}^{(9)}$.

Some authors published a systematic review of all articles of bevacizumab for exudative AMD. A total of 561 articles were retrieved. Three randomised controlled trials (RCT) and 23 before-and-after studies of patients $(n=1,435)$ who had received bevacizumab were published. The overall conclusion is that visual acuity improves and central retinal thickness decreases in patients with exudative AMD after bevacizumab. For the 23 studies with intravitreal injections, the change in visual acuity (VA) was +8.6 letters (range +2 to +26 ) and the change in central retinal thickness was $-90 \mu \mathrm{m}$ (range -46 to -190$)^{(10)}$.

The progressive loss of central vision has a measurable impact on quality of life (QOL), affecting principally mental health dimensions. However, VA alone may not provide an adequate basis to evaluate QOL. Other symptoms of CNV secondary to AMD (such as reduced contrast sensitivity, photopsias, decreased colour vision, size and characteristics of central scotoma, and increased glare sensitivity may also reduce QOL. Thus, the determination of other functional outcomes of AMD treatment is clinically relevant ${ }^{(11)}$.

Macular function is not fully characterized by central VA; major visual tasks such as reading rely on the central visual field as well. Testing VA alone disregards paracentral or central scotomata, which strongly affect the patient's self-assessment of visual function ${ }^{(12)}$. Hence, other diagnostic tools were developed to evaluate more accurately the macular function. Micro- or fundus perimetry offers the option to test retinal sensitivity while directly observing the fundus ${ }^{(13)}$. Other authors showed that the intravitreal use of bevacizumab resulted in improvement of multifocal electroretinography (mf-ERG) macular function responses and relatively stable Ganzfield electroretinography (G-ERG) responses. The macular electrophysiological response suggests that macular function improves with treatment ${ }^{(14)}$.

The purpose of this article is to assess the correlation between the morphological outcome macular thickness on optical coherence tomography (OCT) and the functional outcomes best corrected visual acuity (BCVA) and decibels lost on macular protocol of the Humphrey visual field after treatment with bevacizumab for AMD.

\section{METHODS}

In this non-randomized, prospective, interventional clinical study, thirteen patients treated for neovascular age-related macular degeneration at the Instituto de Oftalmologia Lavinsky between March, 2007 and June, 2007 were included. They underwent $1.25 \mathrm{mg}(0.05 \mathrm{cc})$ intravitreal injections of bevacizumab at baseline and on week 6 .

The inclusion criteria were: age 50 years and older, subfoveal CNV attributable to AMD diagnosed by fluorescein angiography, presence of subretinal fluid, cystic maculopathy, or central retinal thickness $250 \mu \mathrm{m}$ on OCT, best-corrected vision, using early treatment diabetic retinopathy study (ETDRS) charts, between 20/40 and 20/400 (Snellen equivalent), no prior anti-VEGF treatment, presence of central fixation demonstrated by the OCT performed by an ophthalmologist and the ability to understand and sign consent form.

The exclusion criteria were: prior VEGF treatment for CNV, corneal, lenticular, or vitreous opacification that prevents good interpretation of fluorescein or indocianin angiograms or OCT, history of vitrectomy, diabetic retinopathy and cardiovascular, cerebrovascular, or peripheral vascular event less than six months prior to enrolment.

The procedures prior to the injections were BCVA, OCT III and a Macular threshold protocol Humphrey visual field (MPHVF) analyzing the losses in decibels of the visual field protocol.

The OCT (OCT Stratus $3^{\circledR}$, Carl Zeiss Meditec, Dublin, CA) was performed by an ophthalmologist using the macular thickness program. The patient fixation (concentric or eccentric) was determined by this examinator. Visual acuity was also measured by an ophthalmologist in a Snellen chart with the best refractive correction. The Humphrey AII $745^{\circledR}$ (Carl Zeiss Meditec, Dublin, CA) was used to perform the Macular threshold protocol of the Humphrey visual field.

The patients were informed about the study and signed a consent according the good clinical practice principles and the tenets of the Declaration of Helsinki.

The injections were performed at the OR using a sterile draping and standard sterilization of the fornices with iodinepovidone $5 \%$. The injection was via pars-plana with a 30 gauge needle 3.5 or $4.0 \mathrm{~mm}$ from the limbus (pseudo-phakic and phakic, respectively) of $0.05 \mathrm{cc}(1.25 \mathrm{mg})$ of bevacizumab. Thirty minutes after injection and a day after injection patients had their intraocular pressures measured and the optic disc and retinal vessels and posterior pole examined.

For the analysis of the data we considered the visual acuities in $\log$ MAR, the central millimetre of the OCT and the sum of the losses in decibels on the Macular protocol of Humphrey visual field.

The statistical tests used were paired and non-paired t-test, Wilcoxon signed ranks test and the Spearman's rho non- 
parametrical test. The statistical analysis was performed using the SPSS $14.0^{\circledR}$ (SPSS, Chicago, IL).

\section{RESULTS}

The patients included in the study underwent both injections (baseline and week-6) on schedule. There was no withdrawal from the study. There were no complications such as intraocular pressure elevation, cataract, uveitic reaction, retinal detachment, vitreous hemorrhage or endophthalmitis an after the procedure. The patients also had no systemic serious adverse events after the injections.

The best corrected visual acuities at baseline ranged from $20 / 25$ to $6 / 120(0.1$ to $1.3 \log$ MAR $)$, the mean was 0.982 $\operatorname{logMAR}( \pm 0.4262)$. On week 6 they ranged from $20 / 50$ to $6 / 120$ (0.4 to $1.4 \log$ MAR), the mean was $1.027 \log$ MAR $( \pm 0.2936)$. On Wilcoxon signed ranks test there was no correlation between the results with a $\mathrm{p}=0.67$ (Graph 1).

The OCT central thickness mean and median at baseline were 329.36 and $298( \pm 113.685)$ respectively. On week 6 this values were 268.18 and $262( \pm 81.54)$. The OCT improvement from baseline to week 6 was significant with a $\mathrm{p}=0.032$ (Graph 2).

The sum of the decibels lost on the MPHVF ranged from 17 to 288 decibels at baseline, mean $142.73 \pm 84.277$, median 103. On week 6 there was an improvement with a mean loss of 95 decibels \pm 65.272 , median 81 . This difference was significant with a $\mathrm{p}=0.003$ on Wilcoxon signed ranks test (Graph 3).

The correlation analysis between the variables studied demonstrated that the BCVA and the decibel loss on the MPHVF were significantly related both at baseline and on week 6 with $p=0.041$ and $p=0.019$ respectively. However, the OCT central thickness had no significant correlation with the BCVA and with the decibel loss on MPHVF at baseline and on week 6 .

\section{DISCUSSION}

Intravitreal bevacizumab is a well accepted treatment for exudative AMD ${ }^{(15)}$. Previous studies have shown favourable outcomes with both $1.25 \mathrm{mg}$ and $2.5 \mathrm{mg}$ doses ${ }^{(16-17)}$. Bevacizumab treatment probably improves macular anatomy by decreasing leakage from the CNV and by preventing its further neovascular growth ${ }^{(18)}$.

The OCT central retinal thickness is a morphological outcome used for follow-up evaluation of the treatment. However, the functional outcome used nowadays is the BCVA. This outcome is weak in evaluating the global function of the macula. It does represent a small area densely populated by cones $\left(50.000\right.$ cones $\left./ \mathrm{mm}^{2}\right)$ but it neglects other important functional aspects of vision like contrast sensitivity, stereopsia and visual field. A prospective case series of 80 patients treated with bevacizumab showed that was no correlation between final BCVA and baseline macular thickness ${ }^{(18)}$.

The use of MPHFV in AMD was previously study by Tolentino et al. They assessed form recognition deficits by the

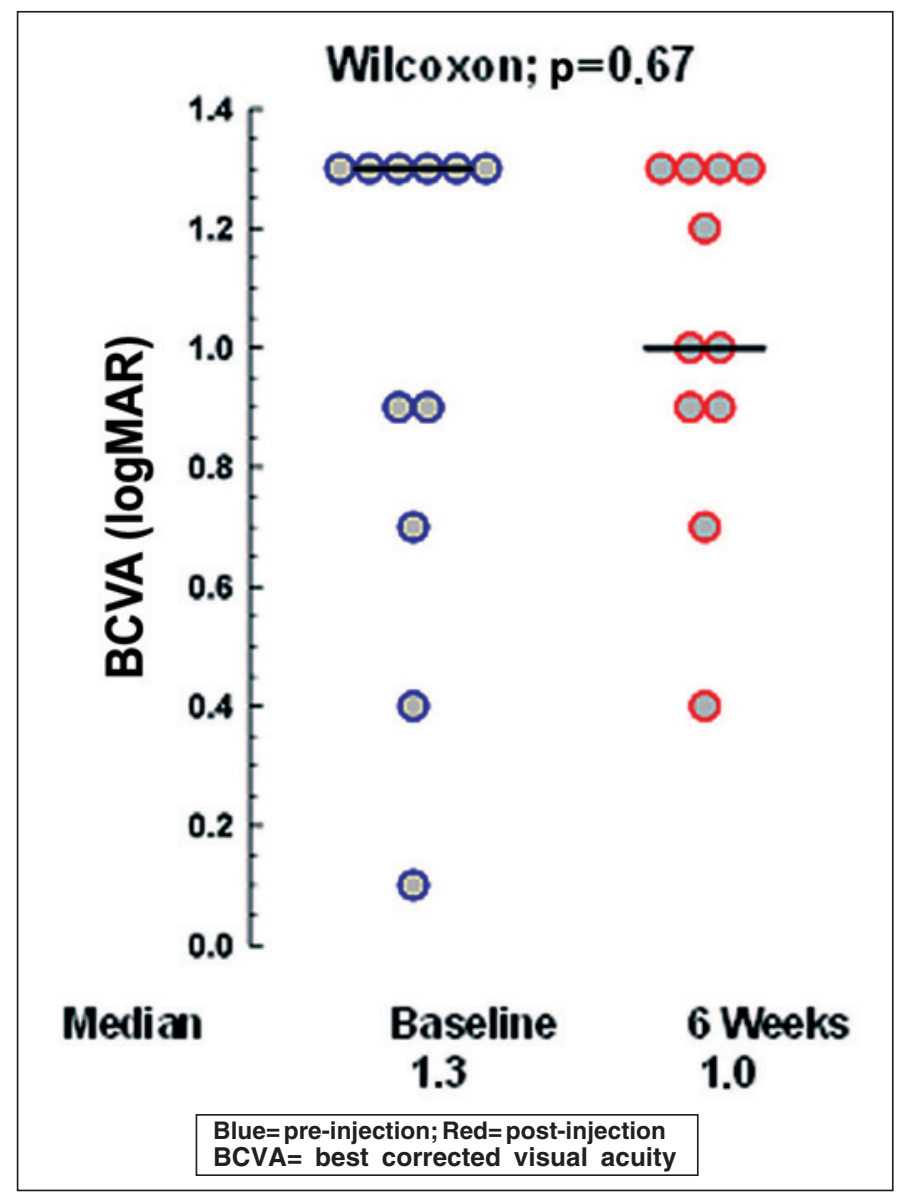

Graph 1 - BCVA at baseline and on week 6

Amsler grid and by a perimetric test of letter recognition and sensitivity deficits by the macular threshold test of the Humphrey field analyzer in 59 patients with AMD and visual acuities of 20/40 or better. The number of defects on each test was compared with the area of RPE atrophy and with the area of drusen determined from fundus photographs. The number of visual field defects by each test was significantly correlated with the area of atrophy, but not with the area of drusen ${ }^{(19)}$.

The improvement of the global macular function, namely the less decibels lost in the second MPHVF test may be an indicator of better quality of life. The retention of macular function may be important for daily living tasks as well as for being able to use low vision aids.

Some authors determined the incremental gain in qualityadjusted life years using the 2-year results from a subgroup of 243 patients with predominantly classic subfoveal CNV secondary to AMD in the treatment of AMD with photodynamic therapy (TAP) Investigation despite the lack of VA improvement. This may be related with the above $\mathrm{e}^{(20-21)}$.

The MPHVF is a very simple, low-cost and well-known diagnostic tool in ophthalmology. The microperimeter (Nidek inc., Padova, Italia), the scanning laser ophthalmoscope (SLO 101, Rodenstock, Ottobrunn, Germany), and the mf-ERG are 


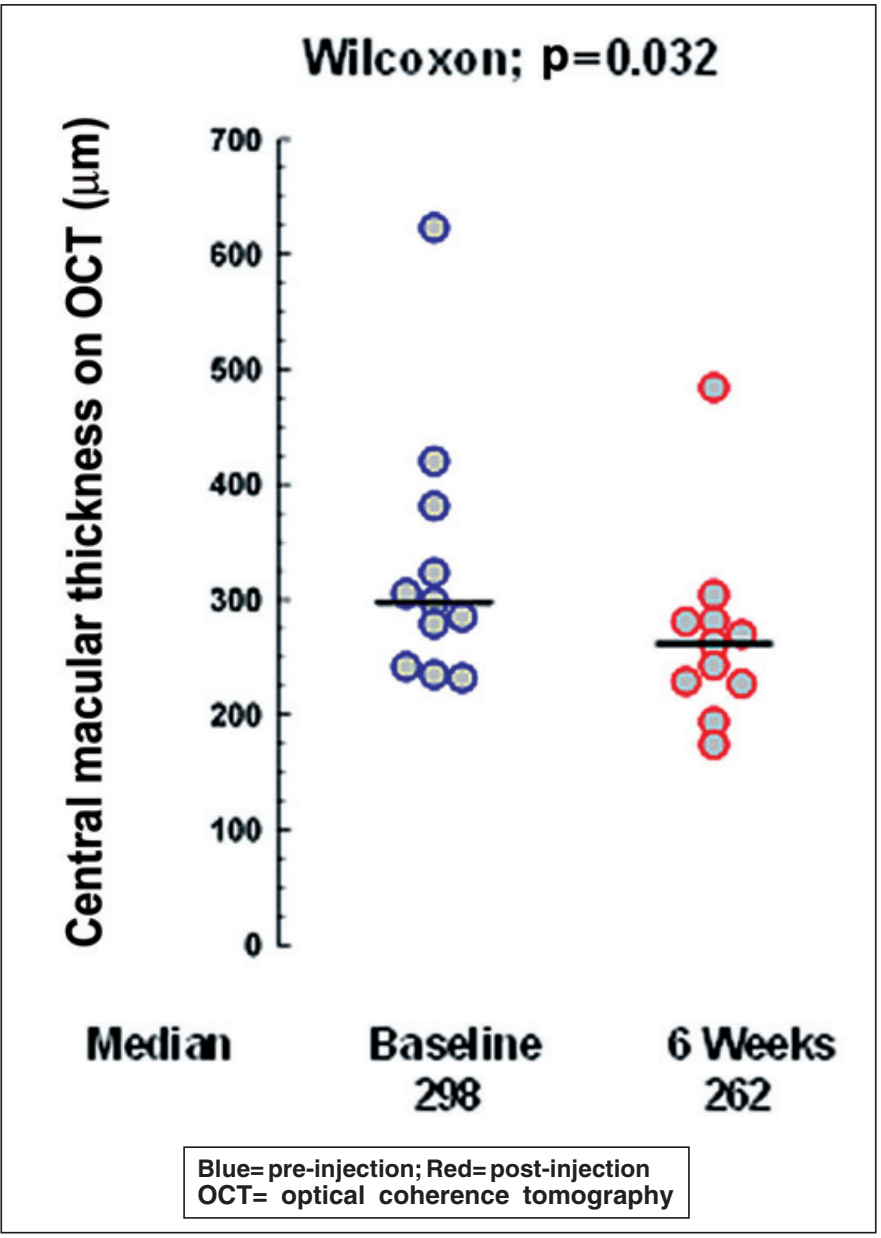

Graph 2 - OCT central macular thickness at baseline and on week 6

also tools that evaluate efficiently the global macular function. However, those tools are less accessible, more expensive and technically harder to perform than the MPHVF. Thus, in a highly prevalent pathology such as AMD a tool with greater external validity is imperative. The limitation of this tool is the excentric fixation. This limitation can be diagnosed during the OCT preformed by an experienced examinator.

The global decibel loss from the MPHVF is a comparison with the average normative data for gender and age. The sum of those losses provides an objective, numeric data for following the patient up individually. Furthermore, it can be used as an outcome to analyze a population being studied for any pathology involving loss of macular function.

\section{CONCLUSION}

In the present article the authors demonstrated that the decibel loss on the MPHVF from the baseline to the 6 week injection was a significant functional outcome. Thus, the correlation of morphological and functional outcomes may be further studied by using the former clinical tool. Like previous reports, in our population the BCVA improvement was not statistically significant.

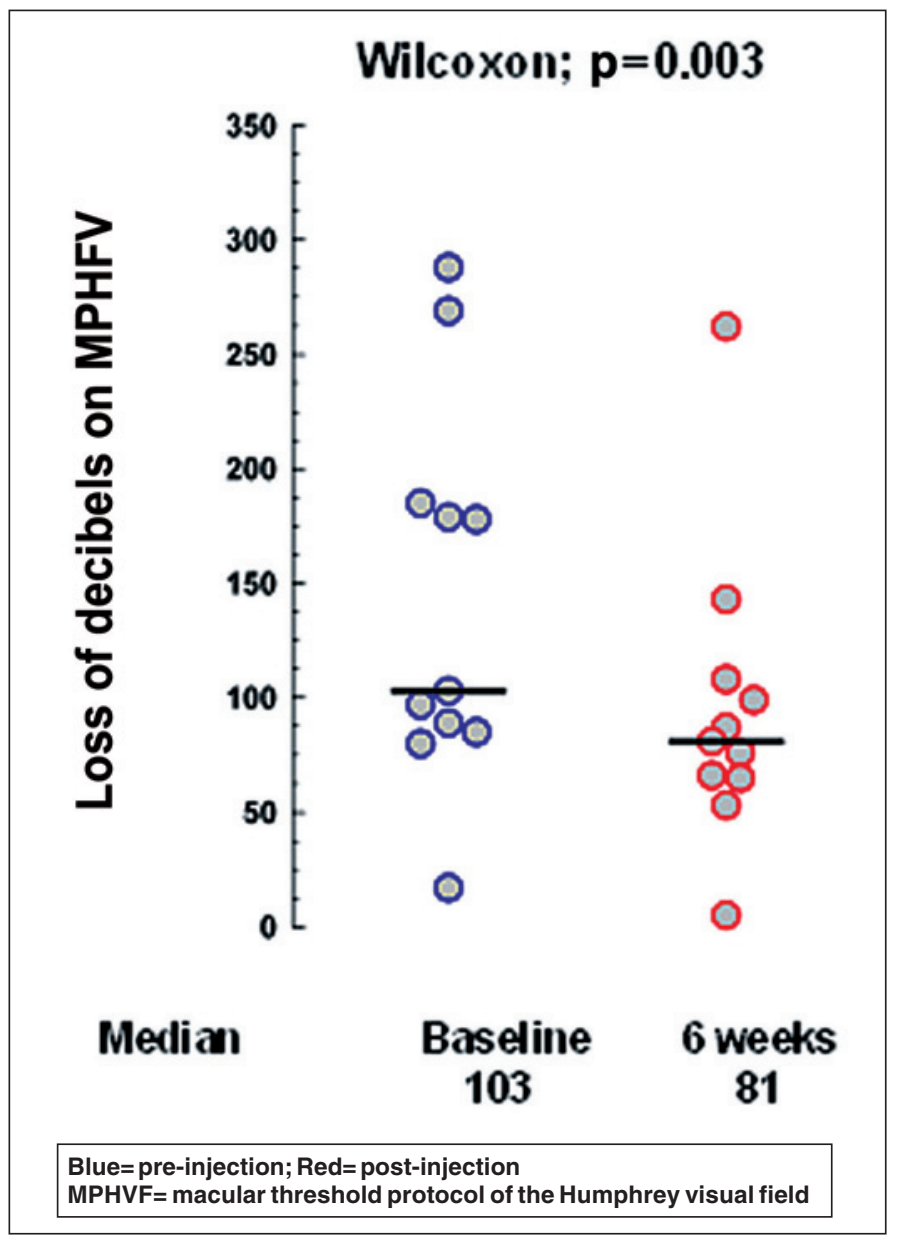

Graph 3 - MPHVF decibel loss at baseline and on week 6

\section{RESUMO}

Objetivo: Avaliar se a perda de decibéis no protocolo macular do campímetro de Humphrey (PMCH) é um resultado funcional confiável para o tratamento com bevacizumab intravítreo. Métodos: Treze pacientes foram avaliados na visita de base e na semana 6 após a injeção intravítrea de $1,25 \mathrm{mg}$ de bevacizumab realizando a melhor acuidade visual corrigida, espessura macular central na tomografia de coerência óptica e análise da perda de decibéis no PMCH. Estes desfechos foram analisados separadamente e em correlação usando o teste Wicoxon signed ranks. Resultados: A melhora da espessura central no OCT e do $\mathrm{PMCH}$ na semana 6 em relação a visita de base foi significante com $\mathrm{p}=0,032$ e $\mathrm{p}=0,003$ respectivamente. A acuidade visual não mostrou uma melhora estatisticamente significante. A correlação entre a acuidade visual e o $\mathrm{PMCH}$ foi significante na visita de base $(\mathrm{p}=0,041)$ e na visita de 6 semanas $(p=0,019)$. Conclusão: O PMCH melhorou significantemente apesar do fato de que a melhor acuidade visual corrigida não apresentou tal melhora. O PMCH correlacionou-se com a acuidade visual de forma estatisticamente significativa. $\mathrm{O}$ OCT foi significativo para demonstrar melhora porém não se 
correlacionou com o PMCH e com a acuidade visual. Estes achados sugerem que o PMCH pode ser uma ferramenta mais confiável na avaliação da função macular global após injeção intravítrea de bevacizumab.

Descritores: Degeneração macular; Tomografia óptica; Corpo vítreo; Acuidade visual; Perimetria; Injecções; Neovascularização de coróide; Anticorpos monoclonais

\section{REFERENCES}

1. Grisanti S, Tatar O. The role of vascular endothelial growth factor and other endogenous interplayers in age-related macular degeneration. Prog Retin Eye Res. 2008;27(4):372-90

2. Green WR, Enger C. Age-related macular degeneration histopathologic studies. The 1992 Lorenz E. Zimmerman Lecture. Ophthalmology. 1993;100(10):15-1935.

3. Campochiaro PA. Ocular neovascularization and excessive vascular permeability. Expert Opin Biol Ther. 2004;4(9):1395-402.

4. D'Amore PA. Mechanisms of retinal and choroidal neovascularization. Invest Ophthalmol Vis Sci. 1994;35(12):3974-9.

5. Adamis AP, Shima DT, Tolentino MJ, Gragoudas ES, Ferrara N, Folkman J, et al. Inhibition of vascular endothelial growth factor prevents retinal ischemiaassociated iris neovascularization in a nonhuman primate. Arch Ophthalmol. 1996;114(1):66-71.

6. Tolentino MJ, Adamis AP. Angiogenic factors in the development of diabetic iris neovascularization and retinopathy. Int Ophthalmol Clin. 1998;38(1):77-94.

7. Hofman P, Blaauwgeers HG, Tolentino MJ, Adamis AP, Nunes Cardozo BJ, Vrensen GF, et al. VEGF-A induced hyperpermeability of blood-retinal barrier endothelium in vivo is predominantly associated with pinocytotic vesicular transport and not with formation of fenestrations. Vascular endothelial growth factor-A. Curr Eye Res. 2000;21(2):637-45.

8. Penfold PL, Madigan MC, Gillies MC, Provis JM. Immunological and aetiological aspects of macular degeneration. Prog Retin Eye Res. 2001;20(3):385-414.
9. Yi X, Ogata N, Komada M, Yamamoto C, Takahashi K, Omori K, et al. Vascular endothelial growth factor expression in choroidal neovascularization in rats. Graefes Arch Clin Exp Ophthalmol. 1997;235(5):313-9.

10. Schouten JS, La Heij EC, Webers CA, Lundqvist IJ, Hendrikse F. A systematic review on the effect of bevacizumab in exudative age-related macular degeneration. Graefes Arch Clin Exp Ophthalmol. 2009;247(1):1-11.

11. Berdeaux GH, Nordmann JP, Colin E, Arnould B. Vision-related quality of life in patients suffering from age-related macular degeneration. Am J Ophthalmol. 2005;39(2):271-9.

12. Slakter JS, Stur M. Quality of life in patients with age-related macular degeneration: impact of the condition and benefits of treatment. Surv Ophthalmol. 2005;50(3):263-73.

13. Rohrschneider K, Bültmann S, Springer C. Use of fundus perimetry (microperimetry) to quantify macular sensitivity. Prog Retin Eye Res. 2008;27(5):536-48.

14. Maturi RK, Bleau LA, Wilson DL. Electrophysiologic findings after intravitreal bevacizumab (Avastin) treatment. Retina. 2006;26(3):270-4.

15. Wang Y, Fei D, Vanderlaan M, Song A. Biological activity of bevacizumab, a humanized anti-VEGF antibody in vitro. Angiogenesis. 2004;7(4):335-45.

16. Spaide RF, Laud K, Fine HF, Klancnik JM Jr, Meyerle CB, Yannuzzi LA, et al. Intravitreal bevacizumab treatment of choroidal neovascularization secondary to age-related macular degeneration. Retina. 2006;26(4):383-90.

17. Rich RM, Rosenfeld PJ, Puliafito CA, Dubovy SR, Davis JL, Flynn HW $\mathrm{Jr}$, et al. Short-term safety and efficacy of intravitreal bevacizumab (Avastin) for neovascular age-related macular degeneration. Retina. 2006;26(5):495-511.

18. Bashshur ZF, Haddad ZA, Schakal A, Jaafar RF, Saab M, Noureddin BN. Intravitreal bevacizumab for treatment of neovascular age-related macular degeneration: a one-year prospective study. Am J Ophthalmol. 2008;145(2):249- 56. Comment in: Am J Ophthalmol. 2008;145(5):937; author reply 938.

19. Tolentino MJ, Miller S, Gaudio AR, Sandberg MA. Visual field deficits in early age-related macular degeneration. Vision Res. 1994;34(3):409-13.

20. Sharma S, Brown GC, Brown MM, Hollands H, Shah GK. The cost-effectiveness of photodynamic therapy for fellow eyes with subfoveal choroidal neovascularization secondary to age-related macular degeneration. Ophthalmology. 2001;108(11):2051-9. Comment in: Ophthalmology. 2003;110(4):626-7; author reply 627-8. Ophthalmology. 2003;110(6):1263-4; author reply 1264-5.

21. Sharma S, Hollands H, Brown GC, Brown MM, Shah GK, Sharma SM. Improvement in quality of life from photodynamic therapy: a Canadian perspective. Can J Ophthalmol. 2001;36(6):332-8. 